\title{
Real Power Loss and Voltage Stability Limit Optimization Incorporating TCSC and SVC through DE Algorithm under Different Operating Conditions of a Power System
}

\author{
L.Jebaraj ${ }^{1}$, C.Christober Asir Rajan ${ }^{2}$, S.Sakthivel ${ }^{3}$ \\ ${ }^{1,3}$ (Department of Electrical and Electronics Engineering, V.R.S. Engineering College, Villupuram, TN, India) \\ ${ }_{2}^{2}$ (Department of Electrical and Electronics Engineering, Pondicherry Engineering College, Puducherry, India)
}

\begin{abstract}
Modern day power system networks are having high risks of voltage instability problems and several network blackouts have been reported. This phenomenon tends to occur from lack of reactive power supports in heavily stressed operating conditions caused by increased load demand and the fast developing deregulation of power systems across the world. This paper proposes an application of Differential Evolution (DE) Algorithm based extended voltage stability margin and minimization of loss by incorporating TCSC and SVC (variable susceptance model) devices. The line stability index $(L Q P)$ is used to assess the voltage stability of a power system. The location and size of Series connected and Shunt connected FACTS devices were optimized by DE algorithm. The results are obtained from the IEEE-30 bus test case system under critical loading and single line outage contingency conditions.
\end{abstract}

Keywords - Differential Evolution Algorithm, FACTS devices, Line stability index, SVC, TCSC, Voltage stability.

\section{INTRODUCTION}

Now a days power system are undergoing numerous changes and becoming more complex from operation, control and stability maintenance standpoints when they meet ever-increasing load demand [1]. Voltage stability is concerned with the ability of a power system to maintain acceptable voltage at all buses in the system under normal conditions and after being subjected to a disturbance. A system enters a state of voltage instability when a disturbance, increase in load demand, or change in system condition causes a progressive and uncontrollable decline in voltage.

The main factor causing voltage instability is the inability of the power system to meet the demand for reactive power [2]-[4]. Excessive voltage decline can occur following some severe system contingencies and this situation could be aggravated, possibly leading to voltage collapse, by further tripping of more transmission facilities, var sources or generating units due to overloading. Many large interconnected power systems are increasingly experiencing abnormally high or low voltages or voltage collapse. Abnormal voltages and voltage collapse pose a primary threat to power system stability, security and reliability. Moreover, with the fast development of restructuring, the problem of voltage stability has become a major concern in deregulated power systems. To maintain security of such systems, it is desirable to plan suitable measures to improve power system security and increase voltage stability margins. [5]-[7]. Voltage instability is one of the phenomena that resulted in major blackouts. Recently, several network blackouts have been related to voltage collapses [8].

Flexible AC Transmission System (FACTS) controllers are capable of supplying or absorption of reactive power at faster rates. The introduction of Flexible AC Transmission System (FACTS) controllers are increasingly used to provide voltage and power flow controls. Insertion of FACTS devices is found to be highly effective in preventing voltage instability [9].Series and shunt compensating devices are used to enhance the Static voltage stability margin.

Voltage stability assessment with appropriate representations of FACTS devices are investigated and compared under base case of study [10]-[12]. One of the shortcomings of those methods only considered the normal state of the system. However voltage collapses are mostly initiated by a disturbance like line outages. Voltage stability limit improvement needs to be addressed during network contingencies. So to locate facts devices consideration of contingency conditions is more important than consideration of normal state of system and some approaches are proposed to locate of facts devices with considerations of contingencies too[13].

Line stability indices provided important information about the proximity of the system to voltage instability and can be used to identify the weakest bus as well the critical line with respect to the bus of the system [14]. The line stability index (LQP) derived by A.Mohmed et al is used for stability assessment [15]. From the family of evolutionary computation, DE Algorithm is used to solve a problem of real power loss minimization and Voltage stability maximization of the system. 
The DE algorithm is a population based algorithm like genetic algorithms using the similar operators; crossover, mutation and selection. Several transformer tap positions along with numbers of reactive power injections at some selected buses in a power system are simultaneously optimized as control variables, so that the multiple objectives are fulfilled, keeping an eye to all specified constraints[16]. Depending upon the higher capital cost of the TCSC and SVC, the installation is not recommended to all possible line outages. Hence line outage contingency screening and ranking carried out to identify the most critical line during whose outage TCSC and SVC controllers can be positioned and system can be operated under stable condition[17]-[19].

The prime objective of this paper is to improve the voltage stability limit and real power limit of a power system during critical loading and line outage contingency conditions performed by insertion of TCSC and SVC devices through differential evolution algorithm.

\section{CRITICAL CONDITIONS}

Voltage collapse is a process in which the appearance of sequential events together with the instability in a large area of system can lead to the case of unacceptable low voltage condition in the network, if no preventive action is committed. Occurrence of disturbance or load increasing leads to excessive demand of reactive power. Therefore system will show voltage instability. If additional sources provide sufficient reactive power support, the system will be established in a stable voltage level. However, sometimes there are not sufficient reactive power resources and excessive demand of reactive power can leads to voltage collapse.

Voltage collapse is initiated due to small changes of system condition (load increasing) as well as large disturbances (line or generator unit outage) under these conditions FACTS devices can improve the system security with fast and controlled injection of reactive power to the system. However when the voltage collapse is due to excessive load increasing, FACTS devices cannot prevent the voltage collapse and only postpone it until they reach to their maximum limits. Under these situations the only way to prevent the voltage collapse is load curtailment or load shedding. So critical loading and contingencies are should be considered in voltage stability analysis.

Recent days, the increase in peak load demand and power transfer between utilities has an important issue on power system voltage stability. Voltage stability has been highly responsible for several major disturbances in power system. When load increases, some of the lines may get overloaded beyond their rated capacity and there is possibility to outage of lines. The system should able to maintain the voltage stability even under such a disturbed condition.

\section{LINE STABILITY INDEX [LQP INDEX]}

Voltage stability can be assessed in a system by calculating the line based voltage stability index. A Mohamed et al [17] derived four line stability factors based on a power transmission concept in a single line. Out of these, the line stability index (LQP) is used in this paper. The value of line index shows the voltage stability of the system. The value close to unity indicates that the respective line is close to its stability limit and value much close to zero indicates light load in the line. The formulation begins with the power equation in a power system. Figure 1 illustrates a single line of a power transmission concept.

The power equation can be derived as;

$$
\frac{X}{V_{i}^{2}} Q_{i}^{2}-Q_{i}+\left(\frac{X}{V_{i}^{2}} P_{i}^{2}+Q_{j}\right)
$$

The line stability factor is obtained by setting the discriminant of the reactive power roots at bus 1 to be greater than or equal to zero thus defining the line stability factor, LQP as,

Figure 1: Single line concept of power transmission

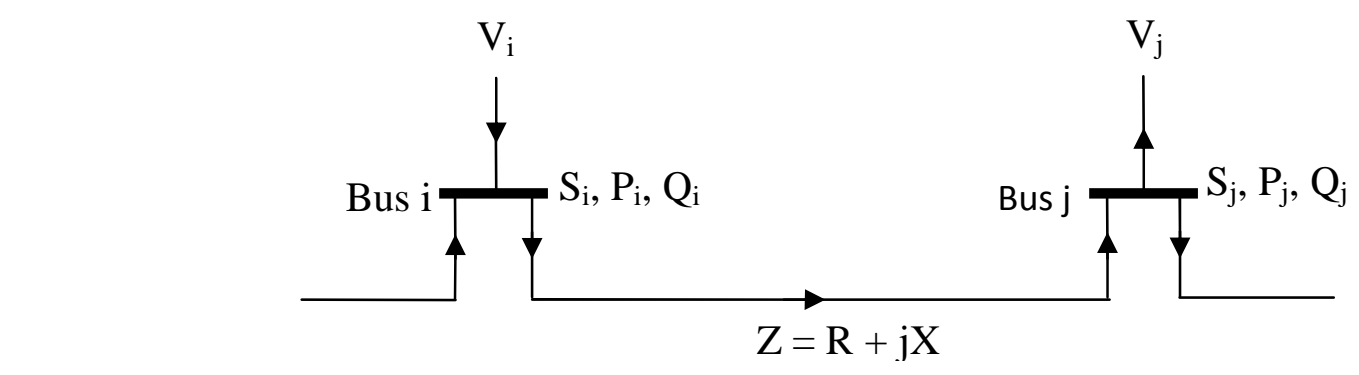

$L Q P=4\left(\frac{X}{V_{i}^{2}}\right)\left(\frac{X}{V_{i}^{2}} P_{i}^{2}+Q_{j}\right)$

IV. STATIC MODEL OF SVC

A variable susceptance $B_{S V C}$ represents the fundamental frequency equivalent susceptance of all shunt modules making up the SVC. This model is an improved version of SVC models. The circuit shown in figure 2 
is used to derive the SVC's nonlinear power equations and the linearised equations required by Newton's load flow method.

Figure 2: Variable susceptance model of SVC

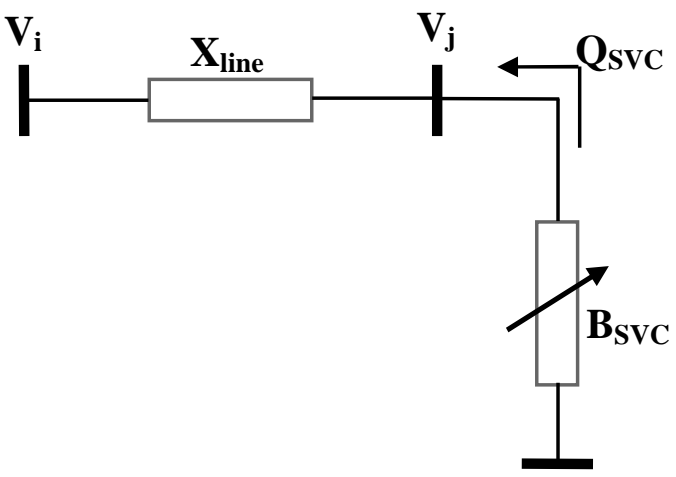

In general, the transfer admittance equation for the variable shunt compensator is

$I_{S V C}=j B_{S V C} V_{j}$

And the reactive power is

$Q_{S V C}=-V_{j}^{2} B_{S V C}$

In $\mathrm{SVC}$ susceptance model the total susceptance $B_{\mathrm{SVC}}$ is taken to be the state variable, therefore the linearised equation of the $\mathrm{SVC}$ is given by

$\left[\begin{array}{l}\Delta P j \\ \Delta Q j\end{array}\right]=\left[\begin{array}{cc}0 & 0 \\ 0 & \theta_{j}\end{array}\right]\left[\begin{array}{c}\Delta \theta j \\ \Delta B s v c / B s v c\end{array}\right]$

At the end of iteration $i$ the variable shunt susceptance $B_{\text {SVC }}$ is updated according to

$B_{S V C}^{(i)}=B_{s v c}^{(i-1)}+\left(\Delta \mathrm{B}_{\mathrm{SVC}} / \mathrm{B}_{\mathrm{SVC}}\right)^{(i)} B_{S V C}^{(i-1)}$

This changing susceptance value represents the total SVC susceptance which is necessary to maintain the nodal voltage magnitude at the specified value (1.0 p.u. in this paper).

\section{V.}

\section{STATIC MODEL OF TCSC}

TCSC is a series compensation component which consists of a series capacitor bank shunted by thyristor controlled reactor. The basic idea behind power flow control with the TCSC is to decrease or increase the overall lines effective series transmission impedance, by adding a capacitive or inductive reactance correspondingly. The TCSC is modeled as variable reactance shown in figure 3 . The equivalent reactance of line $X_{i j}$ is defined as:

Figure 3: Model of TCSC

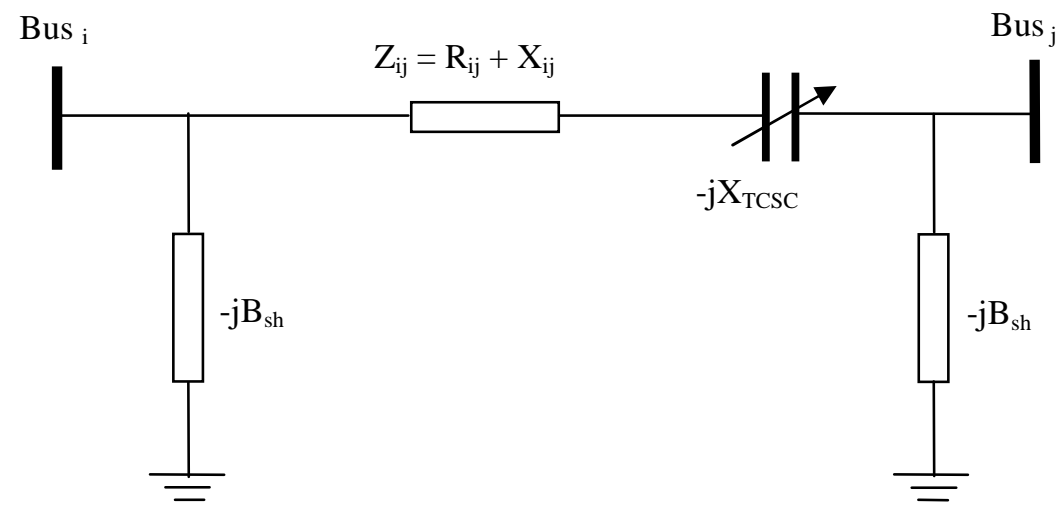

$\mathrm{X}_{\mathrm{ij}}=-0.8 \mathrm{X}_{\text {line }} \leq \mathrm{X}_{\mathrm{TCSC}} \leq 0.2 \mathrm{X}_{\text {line }}$

where, $X_{\text {line }}$ is the transmission line reactance, and $X_{T C S C}$ is the TCSC reactance. The level of the applied compensation of the TCSC usually varies between $20 \%$ inductive and $80 \%$ capacitive. 


\section{PROBLEM FORMULATION}

The objective function of this work is to find the optimal rating and location of TCSC and SVC which minimizes the real power loss, maximizes the voltage stability limit, voltage deviation and line stability index. Hence, the objective function can be expressed as

$F=\operatorname{Minimize}\left[f_{1}+\lambda_{1} f_{2}+\lambda_{2} f_{3}\right]$

The term $\mathrm{f}_{1}$ represents real power loss as

$$
f_{1}=\sum_{\mathrm{k}=1}^{N_{L}} G_{k}\left[V_{i}^{2}+V_{j}^{2}-2 V_{i} V_{j} \cos \left(\delta_{i}-\delta_{j}\right)\right]
$$

The term $\mathrm{f}_{2}$ represents total voltage deviation (VD) of all load buses as

$f_{2}=V D=\sum_{k=1}^{N_{P Q}}\left(V_{i}-V_{\text {ref }}\right)^{2}$

The term $\mathrm{f}_{3}$ represents line stability index (LPQ) as

$f_{3}=L Q P=\sum_{j=1}^{N_{L}} L Q P_{j}$

where $\lambda_{1}$ and is $\lambda_{2}$ are weighing factor for voltage deviation and LQP index and are set to 10 .

The minimization problem is subject to the following equality and inequality constraints

(i) Load Flow Constraints:

$P_{G i}-P_{D i}-\sum_{j=1}^{N_{B}} V_{i} V_{i j} Y_{i j} \cos \left(\delta_{i j}+\gamma_{j}-\gamma_{i}\right)=0$
$Q_{G i}-Q_{D i}-\sum_{j=1}^{N_{B}} V_{i} V_{i j} Y_{i j} \sin \left(\delta_{i j}+\gamma_{j}-\gamma_{i}\right)=0$

(ii) Reactive Power Generation Limit of SVCs:

$Q_{c i}^{\min } \leq Q_{c i} \leq Q_{c i}^{\max } ; i \in N_{S V C}$

(iii) Voltage Constraints:

$V_{i}^{\min } \leq V_{i} \leq V_{i}^{\max } ; i \in N_{B}$

(iv) Transmission line flow limit:

$S_{i} \leq S_{i}^{\max } ; i \in N_{l}$

VII. DIFFERENTIAL EVOLUTION ALGORITHM - AN OVER VIEW

Differential Evolution (DE) is a population based evolutionary algorithm [16], capable of handling non-differentiable, nonlinear and multi-modal objectives functions. DE generates new offspring by forming a trial vector of each parent individual of the population. The population is improved iteratively, by three basic operations namely mutation, crossover and selection. A brief description of different steps of DE algorithm is given below.

\section{Initialization}

The population is initialized by randomly generating individuals within the boundary constraints $X_{i j}^{0}=X_{j}^{\text {min }}+\operatorname{rand}\left(X_{j}^{\text {max }}=X_{j}^{\text {min }}\right) ; i=1,2,3, \ldots N P, j=1,2,3, \ldots D$

where "rand" function generates random values uniformly in the interval $(0,1) ; N P$ is the size of the population; $D$ is the number of decision variables. $X_{j}^{\min }$ and $X_{j}^{\max }$ are the lower and upper bound of the $j^{\text {th }}$ decision variable, respectively.

\section{Mutation}

As a step of generating offspring, the operations of "Mutation" are applied. "Mutation" occupies quite an important role in the reproduction cycle. The mutation operation creates mutant vectors $V_{i}^{k}$ by perturbing a randomly selected vector $X_{a}{ }^{k}$ with the difference of two other randomly selected vectors $X_{b}{ }^{k}$ and $X_{c}{ }^{k}$ at the $k^{\text {th }}$ iteration as per the following equation:

$$
V_{i}^{k}=X_{a}^{k}-\left(X_{b}^{k}-X_{c}^{k}\right) ; i=1,2,3 \ldots . . N P
$$

$X_{a}^{k}, X_{b}{ }^{k}$ and $X_{c}^{k}$ are randomly chosen vectors at the $K^{t h}$ iteration and $a \neq b \neq c \neq i$ and are selected a new for each parent vector. $F$ is the scaling constant that controls the amount of perturbation in the mutation process and improves convergence. 


\section{Crossover}

Crossover represents a typical case of a "genes" exchange. The trial one inherits genes with some probability. The parent vector is mixed with the mutated vector to create a trial vector, according to the following equation:

$U_{i j}^{k}=\left\{\begin{array}{l}V_{i j}^{k}, \text { if rand }<C R \text { or } j=q \\ X_{i j}^{k}, \text { Otherwise }\end{array}\right.$

Where $i=1,2,3 \ldots \ldots \ldots \ldots . . . N P ; j=1,2,3$.

D. $X_{i j}{ }^{k}, V_{i j}{ }^{k} \quad U_{i j}{ }^{k}$ are the $j^{\text {th }}$ individual of target vector, mutant vector, and trial vector at $k^{\text {th }}$ iteration, respectively. $q$ is a randomly chosen index in the range $(1, D)$ that guarantees that the trial vector gets at least one parameter from the mutant vector. CR is the cross over constant that lies between 0 and 1 .

\section{Selection}

Selection procedure is used among the set of trial vector and the updated target vector to choose the best one. Selection is realized by comparing the fitness function values of target vector and trial vector. Selection operation is performed as per the following equation:

$$
X_{i}^{k+1}=\left\{\begin{array}{l}
U_{i}^{k}, \text { if }\left(U_{i}^{k}\right) \leq f\left(X_{i}^{k}\right) ; i=1,2,3 \ldots . . N P \\
X_{i}^{k}, \text { Otherwise }
\end{array}\right.
$$

\section{IMPLEMENTATION OF DIFFERENTIAL EVOLUTION ALGORITHM}

\section{Representing an individual:}

Each individual in the population is defined as a vector containing the values of control parameters including the size of the TCSC and SVC.

\section{Number of individuals:}

There is a trade-off between the number of individuals and the number of iterations of the population and each individual fitness value has to be evaluated using a power flow solution at each iteration, thus the number of individuals should not be large because computational effort could increase dramatically. Individuals of 5,10 and 20 are chosen as an appropriate population sizes.

\section{Feasible region Definition:}

There are several constraints in this problem regarding the characteristics of the power system and the desired voltage profile. Each of these constraints represents a limit in the search space. Therefore the DE algorithm has to be programmed so that the individual can only move over the feasible region. For instance, the network in Fig. 4 has 4 transmission lines with tap changer transformer. These lines are not considered for locating TCSC, leaving 37 other possible locations for the TCSC. In terms of the algorithm, each time that an individual's new position includes a line with tap setting transformer, the position is changed to the geographically closest line (line without transformer). Finally, in order to limit the sizes of the TCSC units, the restrictions of level of compensation is applied to the individuals. The optimal parameter values of differential evolution algorithm shown in table 1 .

\section{Optimal Parameter Values:}

Table.1. Optimal values of DE parameters

\begin{tabular}{|c|c|}
\hline Parameters & Optimal Values \\
\hline Number of Individuals & 50 \\
\hline Cross Over Constant & 0.6 \\
\hline Scaling Constant & 0.3 \\
\hline Number of Iterations & 100 \\
\hline
\end{tabular}

\section{Integer DE:}

For this particular application, the position of individuals is determined by an integer number (line number). Therefore the individuals' movement is approximated to the nearest integer numbers. Additionally, the location number must not be a line with tap setting transformer. If the location is line with tap setting 
transformer, then the individual component regarding position is changed to the geographically closest line without a tap setting transformer.

\section{RESULTS AND DISCUSSIONS}

The proposed work is coded in MATLAB 7.6 platform using $2.8 \mathrm{GHz}$ Intel Core 2 Duo processor based PC. The method is tested in the IEEE 30 bus test system shown in figure 4 . The line data and bus data are taken from the standard power system test case archive. The system has 6 generator buses, 24 load buses and 41 transmission lines. System data and results are based on 100 MVA and bus no 1 is the reference bus. In order to

Figure 4: One line diagram of IEEE 30 Bus Test System

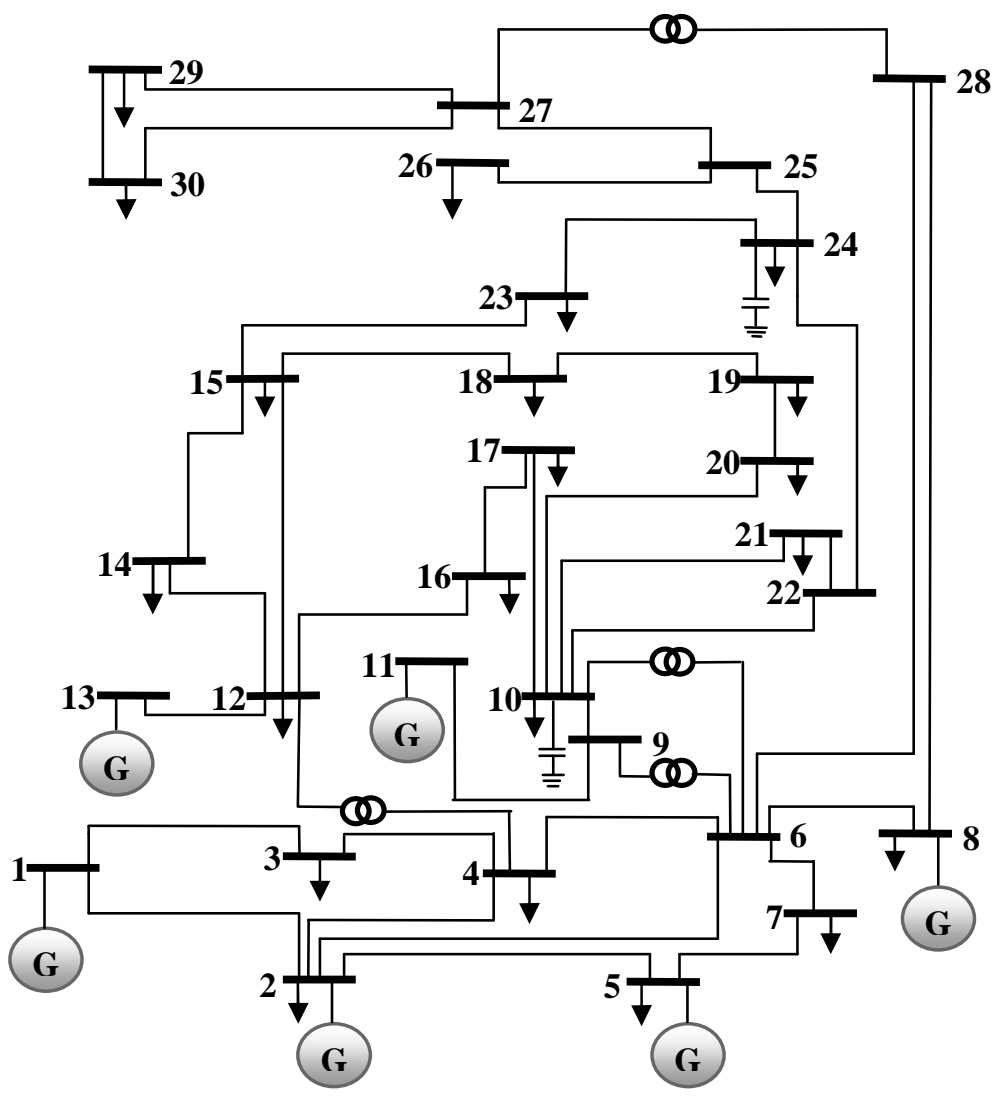

verify the presented models and illustrate the impacts of TCSC and SVC study, three different operating conditions are considered as mentioned below.

Case 1: The system with normal load in all the load buses is considered as normal condition and the NewtonRaphson load flow is carried out with loading factor value equal to 1 .

Case 2: The system with $50 \%$ increased load in all the load buses is considered as a critical condition. Loading of the system beyond this level, results in poor voltage profile in the load buses and unacceptable real power loss level.

Case 3: Contingency is imposed by considering the most critical line outage in the system. This is the most suitable condition for voltage stability analysis of a power system as voltage stability is usually triggered by line outages.

Newton - Raphson program is repeatedly run with the presence and absence of TCSC and SVC devices. The voltage stability limit improvement is assessed by the value of LQP index. The LQP values of all lines under normal conditions with and without FACTS devices are depicted in figure 5. Figure 6 compares the index value of all the lines in the system under critical loading condition. It is evident from the figures that LQP values of most of the lines are reduced after placement of FACTS devices in the system. 
Figure 5: LQP Index Values under Normal Conditions

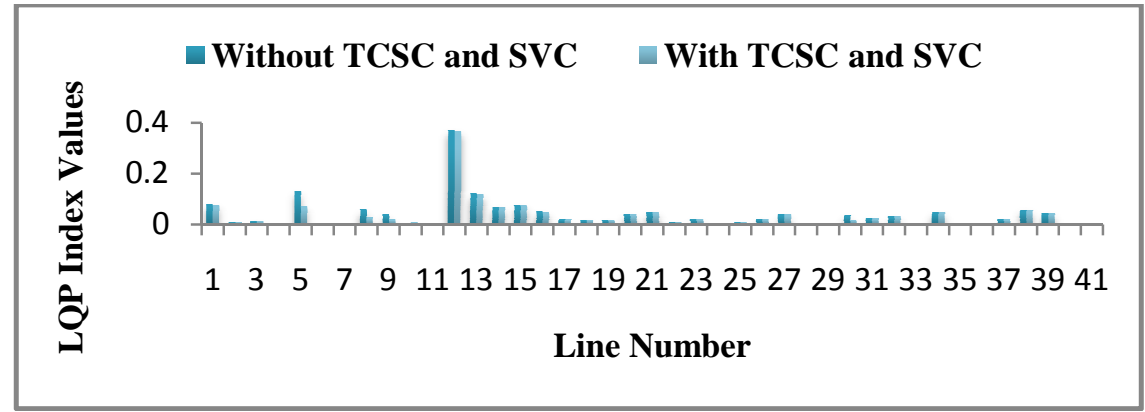

Figure 6: LQP Index Values under Critical Loading Conditions

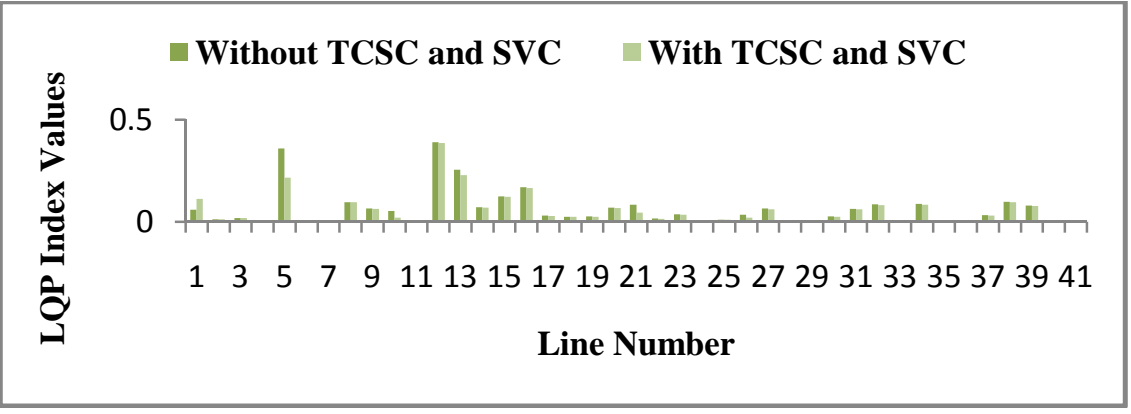

Figure 7: LQP index values under single line outage contingency conditions

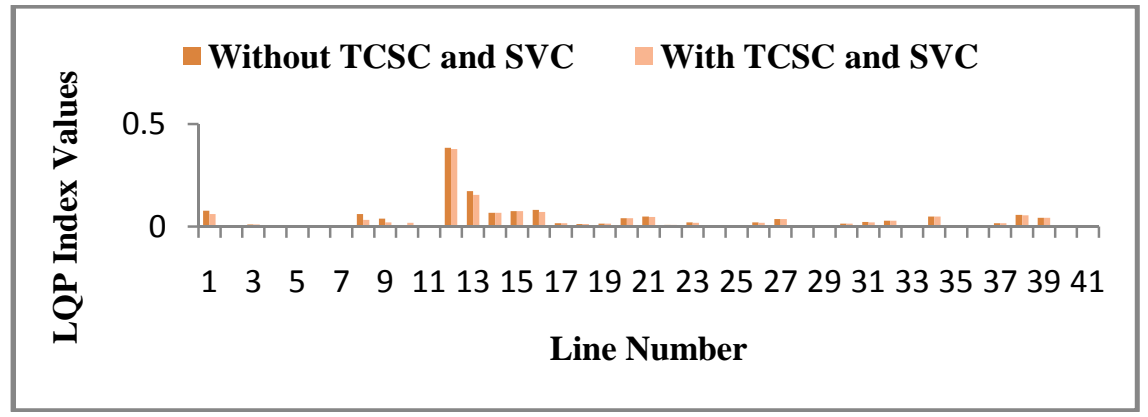

In case 3 , the line outage is ranked according to the severity and the severity is taken on the basis of the line stability index values (LQP) and such values are arranged in descending order. The maximum value of index indicates most critical line for outage. Line outage contingency screening and ranking is carried out on the test system and the results are shown in table 2. It is clear from the results that outage of line number 5 is the most critical line outage and this condition is considered for voltage stability improvement. Outage of other lines has no much impact on the system and therefore they are not given importance.

Table.2. Contingency ranking

\begin{tabular}{|c|c|c|}
\hline Rank & Line Number & LQP Values \\
\hline 1 & 5 & 0.9495 \\
\hline 2 & 9 & 0.6050 \\
\hline 3 & 2 & 0.4993 \\
\hline 4 & 4 & 0.4968 \\
\hline 5 & 7 & 0.4693 \\
\hline
\end{tabular}

Load flow is run on the system with line 5 outaged. Outage of this line results in large real power loss and voltage profile reduction in most of the load buses. The system is under stressed conditions and needs to be 
relieved by some means. Installation FACTS devices at suitable locations can relive the system much from stressed conditions (reduced line losses). LQP values of the lines before and after insertion of FACTS are compared in fig 7 during contingency condition. The reduction in LQP values is encouraging in all the lines in this case.

For quick assessment of voltage stability limit improvement of the system under the three different operating conditions, sum of the LQP index values of all the lines before and after the optimization process is compared in figure 8 . The reduction in the index value indicates the voltage stability limit improvement.

Figure 8: Sum of LQP index values in all cases

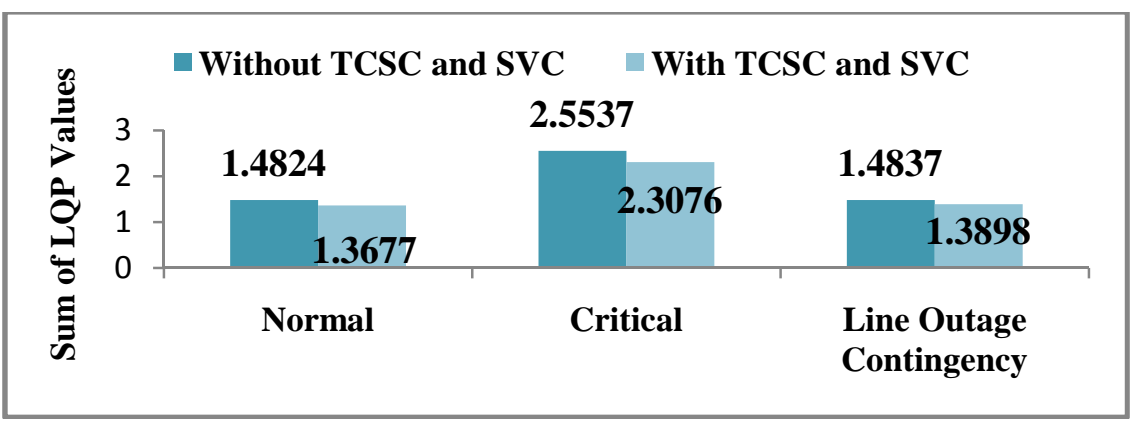

Table 3. Voltage Profile in all cases

\begin{tabular}{|c|c|c|c|c|c|c|}
\hline \multirow[b]{2}{*}{ Bus No. } & \multicolumn{2}{|c|}{ Normal Loading } & \multicolumn{2}{|c|}{ Critical Loading } & \multicolumn{2}{|c|}{$\begin{array}{c}\text { Single Line Outage } \\
\text { Contingency Condition }\end{array}$} \\
\hline & $\begin{array}{c}\text { Without } \\
\text { TCSC } \\
\text { and } \\
\text { SVC }\end{array}$ & $\begin{array}{c}\text { With } \\
\text { TCSC } \\
\text { and } \\
\text { SVC }\end{array}$ & $\begin{array}{c}\text { Without } \\
\text { TCSC } \\
\text { and } \\
\text { SVC }\end{array}$ & $\begin{array}{l}\text { With } \\
\text { TCSC } \\
\text { and } \\
\text { SVC }\end{array}$ & $\begin{array}{c}\text { Without } \\
\text { TCSC } \\
\text { and } \\
\text { SVC }\end{array}$ & $\begin{array}{c}\text { With } \\
\text { TCSC } \\
\text { and } \\
\text { SVC }\end{array}$ \\
\hline 1 & 1.0600 & 1.0600 & 1.0600 & 1.0600 & 1.0600 & 1.0600 \\
\hline 2 & 1.0430 & 1.0430 & 1.0030 & 1.0130 & 1.0430 & 1.0430 \\
\hline 3 & 1.0217 & 1.0227 & 0.9745 & 0.9812 & 1.0069 & 1.0110 \\
\hline 4 & 1.0129 & 1.0142 & 0.9581 & 0.9661 & 0.9958 & 1.0085 \\
\hline 5 & 1.0100 & 1.0100 & 0.9600 & 0.9660 & 0.9600 & 0.9600 \\
\hline 6 & 1.0121 & 1.0139 & 0.9553 & 0.9611 & 0.9909 & 0.9986 \\
\hline 7 & 1.0035 & 1.0122 & 0.9438 & 0.9474 & 0.9661 & 0.9794 \\
\hline 8 & 1.0100 & 1.0100 & 0.9600 & 0.9600 & 0.9900 & 1.0000 \\
\hline 9 & 1.0507 & 1.0516 & 0.9923 & 1.0075 & 1.0388 & 1.0429 \\
\hline 10 & 1.0438 & 1.0446 & 0.9722 & 0.9348 & 1.0306 & 1.0349 \\
\hline 11 & 1.0820 & 1.0820 & 1.0520 & 1.0620 & 1.0820 & 1.0820 \\
\hline 12 & 1.0576 & 1.0583 & 1.0040 & 1.0203 & 1.0495 & 1.0523 \\
\hline 13 & 1.0710 & 1.0710 & 1.0470 & 1.0610 & 1.0710 & 1.0710 \\
\hline 14 & 1.0429 & 1.0435 & 0.9754 & 0.9961 & 1.0339 & 1.0370 \\
\hline 15 & 1.0385 & 1.0385 & 0.9670 & 0.9882 & 1.0282 & 1.0317 \\
\hline 16 & 1.0445 & 1.0453 & 0.9769 & 1.0030 & 1.0341 & 1.0375 \\
\hline 17 & 1.0387 & 1.0395 & 0.9650 & 0.9970 & 1.0262 & 1.0303 \\
\hline 18 & 1.0282 & 1.0285 & 0.9489 & 0.9711 & 1.0167 & 1.0205 \\
\hline 19 & 1.0252 & 1.0257 & 0.9434 & 0.9660 & 1.0131 & 1.0171 \\
\hline 20 & 1.0291 & 1.0297 & 0.9493 & 0.9719 & 1.0167 & 1.0208 \\
\hline 21 & 1.0293 & 1.0300 & 0.9489 & 0.9713 & 1.0163 & 1.0207 \\
\hline 22 & 1.0353 & 1.0361 & 0.9572 & 0.9789 & 1.0215 & 1.0278 \\
\hline 23 & 1.0291 & 1.0298 & 0.9488 & 0.9710 & 1.0163 & 1.0208 \\
\hline 24 & 1.0237 & 1.0245 & 0.9369 & 0.9574 & 1.0091 & 1.0149 \\
\hline 25 & 1.0202 & 1.0213 & 0.9328 & 0.9482 & 1.0323 & 1.0091 \\
\hline 26 & 1.0025 & 1.0037 & 0.9034 & 0.9193 & 0.9844 & 0.9913 \\
\hline 27 & 1.0265 & 1.0278 & 0.9446 & 0.9565 & 1.0068 & 1.0142 \\
\hline 28 & 1.0109 & 1.0123 & 0.9510 & 0.9564 & 0.9901 & 0.9983 \\
\hline 29 & 1.0068 & 1.0081 & 0.9109 & 0.9233 & 0.9866 & 0.9942 \\
\hline 30 & 0.9953 & 0.9966 & 0.8915 & 0.9042 & 0.9750 & 0.9826 \\
\hline
\end{tabular}


FACTS devices help the system to maintain acceptable voltage profile in the load buses. Under normal operating conditions most of the bus voltage magnitudes are within the normal value. During critical and contingency conditions voltage magnitude of remote load buses are below 0.95 (lower bound of allowable value). These bus voltages are improved after the FACTS devices are installed. It is obvious from table 3 , that voltage profile of the system in all the three cases are improved better.

Reduction in reactive power loss indicates that power flow through the heavily loaded lines are diverted through the under loaded lines and the result is improved voltage profile. In loss minimization point of view through insertion of TCSC and SVC, the real power loss under normal loading is decreased by $0.038 \mathrm{MW}$ which is $0.216 \%$ of total real power loss. Similarly under critical loading and line outage contingency conditions the real power loss decreased by $1.262 \mathrm{MW}$ and $0.629 \mathrm{MW}$ respectively. The percentages of reduction under these cases are $2.69 \%$ and $1.93 \%$ respectively. The real and reactive power losses under all cases are shown in table 4.

Table 4. Real and Reactive Power Loss value of all cases

\begin{tabular}{|c|c|c|c|c|c|c|}
\hline \multirow[b]{2}{*}{$\begin{array}{c}\text { Loss } \\
\text { Parameters }\end{array}$} & \multicolumn{2}{|c|}{ Normal Loading } & \multicolumn{2}{|c|}{ Critical Loading } & \multicolumn{2}{|c|}{$\begin{array}{c}\text { Single Line Outage } \\
\text { Condition }\end{array}$} \\
\hline & $\begin{array}{c}\text { Without } \\
\text { TCSC } \\
\text { and } \\
\text { SVC }\end{array}$ & $\begin{array}{c}\text { With } \\
\text { TCSC } \\
\text { and } \\
\text { SVC }\end{array}$ & $\begin{array}{c}\text { Without } \\
\text { TCSC } \\
\text { and } \\
\text { SVC } \\
\end{array}$ & $\begin{array}{c}\text { With } \\
\text { TCSC } \\
\text { and } \\
\text { SVC }\end{array}$ & $\begin{array}{c}\text { Without } \\
\text { TCSC } \\
\text { and } \\
\text { SVC }\end{array}$ & $\begin{array}{c}\text { With } \\
\text { TCSC } \\
\text { and } \\
\text { SVC }\end{array}$ \\
\hline $\mathrm{P}_{\text {loss }}(\mathrm{MW})$ & 17.514 & 17.476 & 46.900 & 45.638 & 32.569 & 31.940 \\
\hline $\mathrm{Q}_{\text {loss }}(\mathrm{MVAR})$ & 68.691 & 68.513 & 180.831 & 169.179 & 112.229 & 109.836 \\
\hline
\end{tabular}

From table 5 the most suitable location for TCSC to control power flow is found to be line number 18 for normal loading, line number 5 for critical loading and line number 28 for line outage contingency conditions. Similarly SVC to improve voltage profile are found to be bus number 7 for both normal loading and line outage contingency condition and bus number 17 for critical loading. The sum of line stability index values for all three conditions is depicted in figure 8.

Table 5. Best location and size of TCSC and SVC of all cases

\begin{tabular}{|c|c|c|c|c|c|c|}
\hline \multirow{3}{*}{$\begin{array}{l}\text { Objective } \\
\text { function }\end{array}$} & \multicolumn{4}{|c|}{ TCSC } & \multicolumn{2}{|c|}{ SVC } \\
\hline & \multirow{2}{*}{ Location } & \multirow{2}{*}{$\begin{array}{c}\text { Degrees of } \\
\text { Compensat } \\
\text { ion }\end{array}$} & \multicolumn{2}{|c|}{ Line Reactance } & \multirow{2}{*}{ Location } & \multirow{2}{*}{ Size [MVAR] } \\
\hline & & & $X_{\text {old }}$ & $X_{\text {new }}$ & & \\
\hline $\begin{array}{l}\text { Normal } \\
\text { loading }\end{array}$ & $\begin{array}{c}\text { Between buses } \\
12 \text { and } 15\end{array}$ & 0.1539 & \multirow{3}{*}{0.1304} & \multirow{3}{*}{0.1505} & Bus No. 7 & 15.9749 \\
\hline $\begin{array}{l}\text { Critical } \\
\text { loading }\end{array}$ & $\begin{array}{c}\text { Between buses } \\
2 \text { and } 5\end{array}$ & -0.2414 & & & Bus No. 17 & 13.7207 \\
\hline $\begin{array}{c}\text { Single line } \\
\text { outage } \\
\text { contingency }\end{array}$ & $\begin{array}{c}\text { Between buses } \\
10 \text { and } 22\end{array}$ & -0.4735 & & & Bus No. 7 & 16.9132 \\
\hline
\end{tabular}

The much reduction in real power loss and increase in voltage magnitudes after the insertion of TCSC and SVC proves that FACTS devices are highly efficient in relieving a power network from stressed condition and improving voltage stability limit.

\section{CONCLUSIONS}

In this paper, optimal location of TCSC and SVC for voltage stability limit improvement and loss minimization are demonstrated. The voltage stability limit improvement and real power loss minimization are done under normal, critical loading and line outage contingency conditions. The LQP index is used for voltage stability assessment. The circuit element model of TCSC is considered to improve the voltage stability limit by controlling power flows and maintaining voltage profile. This model is easy to incorporate the effect of TCSC into Newton - Raphson load flow program coding. The performance of TCSC and SVC combination in optimal power flow control for voltage stability limit improvement is proved in the results by comparing the system real power loss and voltage profile with and without the devices. It is clear from the numerical results that voltage 
stability limit improvement is highly encouraging. The voltage stability limit improvement is by the combined action of power flow control of TCSC and reactive power compensation by SVC.

\section{REFERENCES}

[1] Voltage stability of power systems: concepts, analytical tools, and industry experience, IEEE Special Publication 90TH0358-2PWR, 1990

[2] T. V. Cutsem, "Voltage instability: Phenomena, countermeasures, and analysis methods," Proceedings of the IEEE, Vol. 88, pp. 208-227, February 2000.

[3] C. W. Taylor, Power System Voltage Stability. New York: McGraw-Hill, 1994P.

[4] P.Kundur, Power System stability and control, McGraw-Hill, 1994

[5] L.H. Fink, ed., Proceedings: Bulk power system voltage phenomena III, voltage stability, security \& control, ECC/NSF workshop, Davos, Switzerland, August 1994.

[6] Dobson, H.-D. Chiang, "Towards a theory of voltage collapse in electric power systems", Systems and Control Letters, Vol. 13, pp. 253-262, 1989.

[7] CIGRE Task Force38-0210,'Modelling of Voltage Collapse Including Dynamic Phenomena, CIGRE Brochure, No 75, 1993.

[8] Technical Analysis of the August 14, 2003, Blackout: What Happened, Why, and What Did We Learn? A report by the North American Electrical Reliability Council Steering Group, July 13, 2004.

[9] N G. Hingorani, L. Gyugyi, Understanding FACTS: Concepts and Technology of Flexible ACTransmission Systems, IEEE Press, New- York, 2000.

[10] A.Sode-Yome, N.Mithulanathan "Static Voltage Stability Margin Enhancement Using STATCOM, TCSC and SSSC", IEEE/PES Transmission and Distribution Conference and Exhibition: Asia Pacific Dalian, China, 2001.

[11] Musunuri, S, Dehnavi, G, "Comparison of STATCOM, SVC, TCSC, and SSSC Performance in Steady State Voltage Stability Improvement” North American Power Symposium (NAPS), 2010.

[12] C.A.Canizares, Z.Faur, "Analysis of SVC and TCSC Controllers in Voltage Collapse", IEEE Transactions on power systems, Vol.14, No.1, pp.158-165, Feb 1999.

[13] MaysamJafari,Saeed Afsharnia,"Voltage Stability Enhancement in Contingency Conditions using Shunt FACTS Devices",EUROCON - IEEE international conference on computer as a tool, Warsaw, Sep 9-12, 2007.

[14] Claudia Reis, Antonio Andrade and F.P.Maciel, "Line Stability Indices for Voltage Collapse Prediction" , IEEE Power Engineering conference, Lisbon, Portugal, March. 2009.

[15] A.Mohmed, G.B.Jasmon and S.Yusoff, "A static voltage collapse indicator using line stability factors", Journal of industrial technology, Vol.7, No.1, pp.73-85, 1989.

[16] K. Price, R. Storn, "Differential evolution - A simple and efficient adaptive scheme for global optimization over continuous spaces, Technical Report, International Computer Science Institute”, Berkley, 1995.

[17] N.D.Reppen,R.R.Austria,J.A.Uhrin,M.C.Patel,A.Galatic,Performance of methods for ranking a evaluation of voltage collapse contingencies applied to a large-scale network, Athens Power Tech, Athens, Greece, pp.337-343, Sept.1993.

[18] G.C. Ejebe, G.D. Irisarri, S. Mokhtari, O. Obadina, P. Ristanovic,J. Tong, Methods for contingency screening and ranking for voltage stability analysis of power systems, IEEE Transactions on Power Systems, Vol.11, No.1, pp.350-356, Feb.1996.

[19] E.Vaahedi, et al "Voltage Stability Contingency Screening and Ranking", IEEE Transactions on power systems, Vol.14, No.1, pp. 256 - 265, February 1999 